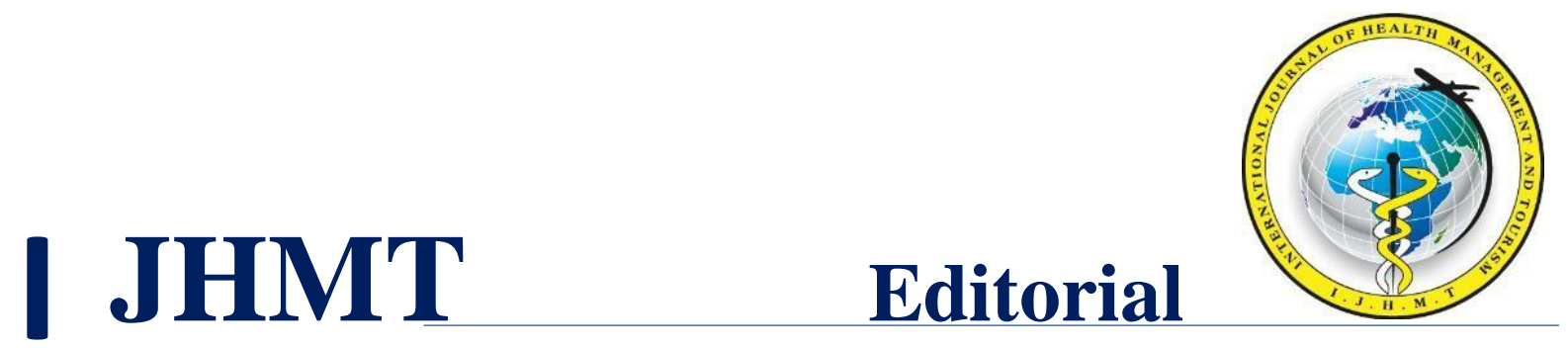

International Journal Of Health Management And Tourism

\title{
TRANSFORMATIONAL WELLNESS TOURISM SYSTEM MODEL IN THE PANDEMIC ERA
}

\section{Deepak CHHABRA*(1)}

* Assoc. Prof. Dr. Arizona State University, U.S.A., deepak.chhabra@asu.edu, ORCID Number: 0000-0003-4565-0325

Received: 20.06 .2020

Accepted: 17.08.2020

Research Article

\begin{abstract}
The key aim of this study is to suggest a transformational wellness tourism system model aimed at preparedness of future travelers. This paper is conceptual and offers an innovative way of planning a new tourism system to facilitate wellbeing and resilience of the tourism industry and its future travelers. Healing and therapeutic potential of non-medical wellness programs is highlighted. The overarching contribution of this study is its conceptual model and its potential to boost preparedness of halted markets for future travel.
\end{abstract}

Keywords: tourism system, transformation, chaos and disequilibrium theories, yoga, wellness programs, public health, COVID 2019 


\section{Introduction}

An overview of a recent past, which will be penned down in history as the old normal, unarguably reveals that tourism was booming before the pandemic. According to UNWTO (2020), international tourism grew to 1.5 billion international tourist arrivals in 2019. Travel today across the globe, both international and domestic travel for leisure purpose, has almost halted. For instance, all international transportation such as airplanes, intercity trains and buses, is grounded or operating at a minimal level. Furthermore, against previous trends and patterns that have shown the poor groups, with food and health insecurities to be more vulnerable and at the receiving end, the current pandemic shows that the most at-risk groups have been international travelers and the affluent social class (Ranasinghe, Damanupola, Wijesundara, Karunarathna et al. 2020).

The global pandemic of novel Corona has paralyzed the entire socio-economic structures and damaged the operation of global supply chains and global enterprises. According to Strielkowski (2020), the re-birthing of tourism calls for a new agenda with key overwhelming focus on local/global health and economy. The World Tourism Organization (UNWTO) is fostering deeper coordination and collaboration with the World Health Organization (WHO). It has issued a call for innovative and grounded leadership from the tourism and hospitality industry so that it plays a big role in future recovery plans and initiatives. Against a backdrop of travel restrictions being introduced, UNWTO stresses on the importance of international dialogue and cooperation and emphasizes that the COVID-19 challenge offers an opportunity to show how solidarity can move beyond international borders. Health measures, in coordination with the WHO (World Health Organization) need to be crafted so that avoidable repercussions on international travel and trade are minimized. According to the UN-WTO, the worldwide travel and tourism industry needs to stand prepared to support recovery various efforts and makes several action-based recommendations broadly categorized into three core areas: managing the crisis and mitigating the impact, providing stimulus and accelerating recovery, and preparing for tomorrow (UNWTO 2020). The role of UN-WTO is crucial; equally important is its outreach and synergistic initiatives with other global organizations such as the World Health Organization (WHO).

Paradoxically, this pandemic is still not over and is unfolding. Countries, which report flattening of the pandemic curve, remain vulnerable and in a defensive mode (Hall, Scott and Gossling 
2020). Today's crisis warns of strategic preparedness for a wellness-centered and resilient/sustainable fresh beginning. Out-of-ordinary ideas are required to support the current and new normal. As implied by the UNWTO campaign- stay home today and travel tomorrow. In other words, the message is: recover or stay immune to make tomorrow's travel possible. A strategically adaptive game plan is required that aims at the long-term wellbeing and resilience of tourists and the tourism system, so that speedy and sustained recovery mechanisms can be developed.

Pandemics are not new to human history. In fact, human history has been punctured with infectious diseases that have caused thousands of millions of people dead. Some familiar examples include the 'Great Plague and the Spanish Flu' (Strielkowski 2020). The coronavirus COVID-19 pandemic is one of the few, human history has witnessed in the 21 st century. For instance, SARs (the Severe Acute Respiratory Syndrome) happened in 2002-2003 and infected approximately 8000 people and caused 774 deaths in 26 countries (Wilder-Smith, 2006). In general, viral diseases have proved to be risky and unpredictable, compared to the ones generated by bacteria (Strielkowski 2020). The viruses are known to be inactive and harmless when secluded but if they get a host, they can attach themselves and rapidly multiply. But time and time again, mankind has demonstrated immense resilience for recovery and adaptability. Today's crisis stresses on healing and sustained health for future prosperity. Therefore, the overarching question in today's pandemic times is how to build and sustain healthy and robust consumer sentiments so that when the world is ready to travel, they serve as a push motivation factors and generate demand for health/wellness trips to authentic domestic and eventually international destinations. Today's crisis calls for a new tourism system premised on health, self-development, social distance, and awareness that humans are only one part of the natural ecosystem. A transformed tourism systems approach holds potential to simultaneously embrace four interrelated dimensions into consideration: health, climate, economy, and ICT (Internet Communications Technology).

The key aim of this study, therefore, is to suggest a transformational tourism system model premised on preparedness facilitated by the healing and therapeutic potential of non-medical wellness programs. This paper is conceptual and offers an innovative way of planning a new tourism system premised on the overall wellbeing and resilience of the tourism industry and its 
future travelers. It critically examines emerging literature in the context of COVID 19, using a systems approach. It also discusses different theories relevant to the tourism life cycle model in the context of the pandemic times to gather insights on different ways a host community is likely to respond when tourism lands on its turf. The overarching significance of this study is its conceptual transformational wellness tourism system model and its potential to boost preparedness of halted markets for future travel.

\section{Literature Review}

This section offers an overview of pandemics and their impact on tourism. This is followed by a discussion of popular tourism system models and their core components. Chaos, complexity and disequilibrium theories are discussed in the context of their significance in shaping the tourism system. Next, significance of ICT and relevant digital platforms is shared in the context of their ability to convey information, offer wellness sessions, and market messages to boost preparedness for future travel. Last, therapeutic potential of yoga as an activity and as a travel experience is examined. All these components are crucial in shaping the conceptualization of the transformational tourism systems model.

\subsection{Pandemics and Tourism}

The tourism industry has witnessed serious disruptive events between 2000 and 2015 although none of them had severely fractured international travel (Gossling et al. 2020). Notable disruptions include September 11 terrorist attacks 2001 on US soil, SARS (the severe acute respiratory syndrome) outbreak in 2002-2003, the global economic recession of 2008/2009, and the MERS (Middle East Respiratory Syndrome) outbreak in 2015 (Gossling, Scott and Hall 2020). According to Burkle (2006), health protection and changes in the global environment play a key role in understanding the association between pandemics and travel patterns. Gossling et al. (2020) note that several warnings have been issued of pandemics and their deadly threat to host communities and non-tourism and tourism sectors (Hall, 2006; Page \& Yeoman, 2007; Scott \& Gossling, 2015) and health scholars (Bloom \& Cadarette, 2019), as well as organizations such as the World Bank (2012) and other institutions (Jonas, 2014).

Several reasons can be attributed the increasing susceptibility of pandemic threats in the $21^{\text {st }}$ century such as: increasing global mobility and worldwide population growth; population density 
in urban areas; increasing reliance on international food supply chains; increasing demand for meat and the nature of global transportation networks that have played a key role in spreading pathogens (Labonte, Mohindra \& Schrecker 2011). SARS, Ebola, Marburg, hantavirus, Zika and avian influenza have resulted from anthropogenic contacts and forces ( $\mathrm{Wu}$, Kinzig, Collins, Minteer et al 2017). This view is supported by $\mathrm{Wu}$ et al., who contend that "high-risk areas for the emergence and spread of infectious disease are where [...] wild disease reservoirs, agricultural practices that increase contact between wildlife and livestock, and cultural practices that increase contact between humans, wildlife, and livestock [intersect]" (2017, p. 18).

The SARS outbreak, in 2002-2003, was mostly concentrated in China, Hongkong and some case clusters in Taiwan and Canada (Gossling et al, 2020). In the context of tourism, for Hongkong, it was noted that SARS did not disrupt the economy on a broad scale although a short-term reduction in visitor numbers was reported which adversely impacted the travel and tourism sectors (Siu and Wong 2004). SARS had an overall estimated global economic cost of US\$100 billion, and US\$48 billion in China (McKercher \& Chon, 2004; Siu \& Wong, 2004). In 2009, The swine flu, produced a mild impact although it caused around 284,000 mortalities across the globe (Viboud \& Simonsen, 2012). Mexico suffered a financial loss because of a decline in approximately one million visitors (Russy and Smith 2013). The European markets were also impacted and underwent a slow recovery phase (Hall et al. 2020). Strategic planning of recovery mechanisms during a pandemic was stressed, a decade ago, by Keogh-Brown, Smith, Edmunds \& Beutels (2010). Two more recent pandemics have been MERS, a viral respiratory disease which emerged in Egypt in 2012 (Berry, Gamieldien \& Fielding 2015) and Ebola. Gossling et al. note that the travel medicine scholars had significantly focused on MERS especially in the context of large pilgrimage events such as the annual hajj pilgrimage to Saudi Arabia. Ebola outbreak in Africa came with high mortality rate across its different phases (Chowell \& Nishiura, 2014).

The travel and tourism industry not only facilitates the spread of a disease and its economic outcome but is also impacted by it on a disrupting scale (Nicolaides, Avraam, Cueto-Felgueroso, Gonzalez et al 2019). The harsh truth right now is that there is no treatment so far to counter the lethal effects of COVID-19 and it has devastated the travel and tourism industry across the globe. As of the second week of May, there is no proven vaccine or treatment although United States is 
pinning its hopes on remdesivir as the trial results of this drug look promising (The Economist 2020). It is manufactured by a drug maker in California (Gilead). It was originally developed to treat Ebola although it did not perform well with Ebola, laboratory tests have reported it to be effective against a broad spectrum of viruses. An ideal solution is to develop a vaccine that can stop people from contracting this virus.

Another glaring reality of COVID-19 is that people are most likely to shed the virus several days before symptoms occur (Bai, Yao, Wei, Tian, et al., 2020; Rothe, Schunk, Sothmann, Bretzel, Froeschl et al. 2020). Consequently, these asymptomatic transmissions have happened before the need to quarantine oneself or embrace social distancing measures in public or wearing the face masks to avoid the virus spread by speaking, coughing, or sneezing. It is being reported that asymptomatic transmissions are happening on a large scale and often go undetected (Li, Pei, Chen, Song, Zhang et al. 2020). As of May 15, approximately $\$ 4.31$ million cases and 295,101 mortalities have been reported across 216 countries (WHO 2020).

The American Enterprise Institute has outlined four phases of recovery in terms of accomplishing the COVID-19 response and roadmap of measurable milestones or conditions to move to the next phase towards restarting the economy:

Phase 1: Slow the spread- Much of the world is currently in phase one (slow the spread), that is, predominant focus has been on flattening the curve as cases continue to rise. That said, some countries and places have reported steady decline in positive cases such as Spain, Italy, New York and Washington (USA).

Phase 2: Initial state/country level reopening- phase two is subject to four conditions: (1) continued decrease in new cases for at least 14 days, (2) Crisis regulations are need for hospitals to treat all patients requiring hospitalization, (3) it is possible to test all people who demonstrate or report COVID-19 symptoms, and (4) a mechanism is in place to actively monitor confirmed cases and contact tracing strategies are in place. In phase 2 , the majority of schools, universities, and businesses can reopen although working from home working should continue and if convenient, social gatherings should remain limited to less than 50 people; People over 60 years of age and those with underlying health conditions should continue to minimize their contact within their community. phase two is a critical threshold for restarting the tourism economy at multiple scales such as the 
local, national and limited international level (for instance- intra-European Union travel). Some countries have arguably reached this phase such as South Korea, Switzerland, and New Zealand, but many major domestic tourism markets might not reach this phase for the next three to eight months.

Phase 3: Establish protection and physical distancing- once a vaccine is developed and authorized for use, physical distancing controls and other NPIs can be removed. Once phase three and widespread vaccination is completed, it will be safe relaunch global. Vaccine update

Phase 4: Rebuild readiness for next pandemic- investment in this final phase is needed in ongoing research and disease monitoring, health care infrastructure and workforce, and improve governance and communication structures. Tourism, in particular air travel and airports, must be part of new international monitoring and rapid response plans. This would also include a better understanding of tourism's role in pandemics: Air travel and transport more generally support the spread of pathogens, while the sector also contributes to growing pressure on remaining forest ecosystems (through land use or industrial food sourcing), i.e. developments that are seen to increase the likelihood of future pandemics (Gossling et al. 2020, p. 12-13).

While these phases are happening, it is important for future tourists to heal and stay healthy, both mentally and physically. Hence, the focus right now should be to develop a future oriented therapeutic tourism system that prepares them and offers them recuperated settings at home. Next, I discuss the significance of a systems approach to tourism that which is dynamic and holds potential to harmoniously integrate crisis management mechanisms. Expanding this discourse, I offer an overview of how chaos and disequilibrium and other theories, premised on unpredictability and disruptions, have been integrated into the existing tourism systems. It is argued that this information is crucial to pave the path for developing a transformative system for the current crisis.

\subsection{Tourism Systems}

A tourism system can be defined as a complex system that evolves and remains in a state of flux, thereby requiring proactive and reactive interventions in an ongoing manner. A systems 
approach to tourism encompasses both supply and demand environments and perspectives. Supply side of tourism in visited/visiting communities include "retail and wholesale travel trade, transport, accommodation, attraction, tour and amenity providers, the retail and food service sectors, local, state, and national destination management organizations, the extensive tourism related media and a whole host of other commercial and non-commercial agencies" (Mill \& Morrison 2006, p. 5). A cursory review of documented literature shows that several tourism system models have been developed although the early systems were closed and did not factor chaotic disturbances caused by macro-environment factors beyond the control of different stakeholders of tourism destinations (Leiper 1990).

Gunn's (1979) tourism system model contains five inter-connected components with attractions centralized as the core point of the system. Mill and Morrison (2006) referred to a tourism system as a closed system with inter-related elements: market, travel, destination, and marketing. The authors postulated that each component propels the other component and to understand the system, all parts need to be examined in a simultaneous manner. The premise behind this argument is that "travel movements occur because of the interaction between the characteristics of the origin (visitor's place of residence), the destination (where the visitor will stay and spend most of his/her time), and the transit routes (on the way) that connect them" (2006, p. 7). However, in both cases, attention is not given to the complex and dynamic nature of tourism.

It is contended that the systems are pluralistic in nature and operate at both personal (refers to the manner a tourist functions within his or her own system of tourism) and nonpersonal levels. Some similarities can be noted in the path of the early tourism system models: tourism can be managed and a public sector approach is best; advocate for a common set of goals to plan a harmonious system and it is important to understand the role and contribution of each part in the system (McKercher 1999; Chhabra 2010). Several limitations have also been noted. For instance, the inter-relationships between various sectors and role players within the system are not recognized. Leiper $(1979 ; 1990)$ tried to address this limitation by stressing on the dynamic nature of the tourism phenomenon. He argued that several nuclear parts make a tourist attraction and these stretch beyond the tangible attributes.

It is important to be distinct, for the sake of competitiveness, while being attached to the system. Next, it is important to acknowledge that all things do not work out as planned; there is an 
unpredictable element which needs to be reiterated such as a single or multiple macro environment factors which are beyond the control of a single organization or a group of stakeholders (McKercher 1999: Chhabra 2015). As evidenced in crisis situations with their unforeseen impacts, Russell has argued that is important to examine the disruptions in the tourism life cycle model that integrates theories such as Lamarckian and chaos and complexity. Different analogies offer different perspectives of the chaos concept such as the butterfly effect (small causes can produce large scale effects), lock in state (situations where an incident can have a long-term effect even after the catalyst has stabilized), edge-of-the-chaos (a critical juncture of disequilibrium) phenomena and self-organizing behavior (new configured state) (Chhabra 2010; Prigogine \& Stengers 1985; Russell 2006).

Extrinsic theories such as Lamarckian and chaos and complexity have been instrumental in understanding the process of evolution and dynamism and the manner in which host communities respond to unforeseen disturbances and welcome tourism (Chhabra 2010, 2015; Ravenscroft \& Hadjihambi 2006). Lamarckian model postulates that it is the most adaptive creatures who survive, when disequilibrium happens and that all changes or disruptions are heritable. According to Russell, the core tenets of chaos and complexity theories bring to light the fundamental forces of change and the significance of triggers at crucial stages as a destination undergoes the process of evolution. Chaos can be described as a scenario where a system is dislocated from its equilibrium state by an unplanned and unexpected catalyst (such as COVID-19). Bringing the system back into equilibrium involves assembling of its various key components to establish a "new order" while "incorporating the vestiges of the old" (Russell 2006, p. 167-168).

Unarguably, a tourism system, at any particular point of time, can move to a state of disequilibrium if a macro-environment factor becomes devastatingly dominant such as political or climate-related or biological (such as a pandemic). McKercher has proposed a chaos-centric tourism functioning model underpinned on chaos theory which refers to disturbance sparked by "loss of control," (1999, p. 428). Chaos is a state or situation when a system loses its equilibrium and it is fueled by an unpredictable catalyst (Russell 2006). On a positive note, such upset in systems do not irrevocably damage them. Systems are, for the most part, resilient and can selforganize themselves if timely initiatives are taken to develop adaptive strategies (Chhabra 2015; 
Russell 2006). McKercher presented an open model where travelers move freely to (outputs) supply side of the system. He included several core inter-connected elements: 1) the traveler, 2) the communication vectors, 3) the considerations, 4) the destination or Internal tourism community, 5) the external tourism agencies, 6) other tourism-related externalities, 7) nontourism related externalities, 8) outputs from the system, 9) and rogues or Chaos makers (Chhabra 2015; McKercher 1999). McKercher argues that although the number of actors influencing the system changes at each level, the relationships between elements remain similar, and thus the model continues to hold value. Several scholars recognize that tourism functions in a non-linear and dynamic manner and turmoil and episodes of serious disruption are a fundamental tenet of the system and are important to embrace and adapt to transformation in tourism communities.

Baggio (2008) has also supported the complexity notion and argued that the key role players (such as the tourism operators, support structures, public and private organizations and associations) partner with each other in both linear and non-linear ways. He has stressed on the inclusion of non-traditional tourism elements which exert indirect influence on the system. According to Baggio (2008) a complex adaptive system comprises of multi-faceted elements and transient non-linear relationship between these elements. Chhabra (2010) has examined chaos and disequilibrium within a rural tourism system, using a life cycle approach and notes that a tourism system is always in a state of flux. Her study illustrates that the life cycle phases of a tourism product or destination often happen in a non-linear and non-conventional fashion. In other words, the development phase might not necessarily lead to a maturity phase. A destination, attraction or product can move to a decline stage due the impact of unforeseen disturbances such as a war or a pandemic. Half a decade later, Chhabra (2015) suggests an adaptive Tourism Systems Model stressing on multi-layered supply chain linkages and synergies between a broad spectrum of tourism products and services. She has argued that competitive synergies are important to boost value-based supply chain links, for both suppliers and consumer markets. In summary, a unanimous message from a plethora of studies is that a dynamic tourism system is constantly under the sway of unpredictable factors and it can be disrupted due to chaos and disequilibrium; but these systems are resilient and with appropriate intervention strategies, 
they can return to the conventional normal or transform to a new normal (Baggio 2008; Hall, Scott \& Gossling 2020; Russell 2006).

Hall et al. (2020) have further argued that transformation of a system is not easy. They opine that competitiveness in the market shapes the response of a destination to disaster. For instance, competition from other destinations "may have implications for recovery trajectories as some destinations may deliberately position themselves in low cost items, with little concern for externalities (e.g., introducing a second wave into the resident population), in order to try and increase visitor numbers and employment possibilities as soon as possible. Other places may continue..... to restrict arrivals and hotel reservations to reduce the second wave of infections" (Hall et al. 2020, p. 8). Higgins-Desbioles (2020) calls for a strong social component in the tourism system. She contends that neoliberal governments, have embraced socialized policies to respond to the crisis by developing health, social and educational procedures. By broadly socializing tourism, the industry can be responsive and accountable to the communities where it happens. The biggest hurdle is control. The author argues that the society is often restricted in its management and reaping of benefits because they cannot exercise control on the markets. The notion of socializing tourism requires establishing tourism in the context of the community/society "where it occurs and to harness it for the empowerment and wellbeing of communities" (Higgins-Desbioles 2020, p. 9). In other words, a community-centric prosperity, in terms of economic and wellness, approach needs to be embedded into a tourism system model.

Recent scholars have pointed out that the corporate global approach towards tourism has crashed because global supply chains and global tourism has not passed the pandemic test and a more localized model will offer a path towards tomorrow's tourism (Gossling et al. 2020; Ransinghe et al. 2020). Current scholarship, although sparse, discusses the effects of the pandemic and projects various trajectories for the growth of future tourism. Nevertheless, it is unanimous in suggesting a more localized and health/wellness (of the tourism industry as well as the society) at large focus although it differs on key role players and strategies to jump start tourism. Regardless of the preferred route or path, the crucial importance of digitalization cannot be denied. Different communities and societies across the globe, under lock down or stay-at-home orders, have stayed connected and engaged with the outside world because of Internet. Digitalization of tourism is here to stay and can play a crucial role in shaping the mental and emotional health of disaster- 
struck societies across the globe. Hence, its robust and positive interventions and entertainment can assist in filling the vacuum, social distance has created in these changing and testing times. This element of tourism system continues to hold a crucial position in the tourism system and its utility functions are expanding. According to Popescu, Nicolae and Pavel (2015), digital applications help expand outreach and offer user- friendly interfaces to facilitate stakeholder partnerships. They have transformed the tourism value chain by expediating strategic relationships between tourism organizations. Today, their crucial role lies in their utility as a platform for boosting positive psychology and stress relief.

\subsection{The Digital Era}

It cannot be denied that because of unprecedented growth of Internet technology, digital information has permeated all walks of contemporary life. Technological developments in tourism have progressed from online communities to web 3.0 and location-based services and mobile services. These have paved the way for more sophisticated systems such as intelligent systems which "supply tourism consumers and service providers with more relevant information, greater decision-support, greater mobility, and ultimately more enjoyable tourism experiences" (Gretzel 2011, p. 758). Such systems enhance the ability to decipher, to benefit from experience, hold knowledge, and to respond promptly and effectively in a situation (Rudas and Fodor 2008).

Web 2.0 introduced a broad spectrum of electronic applications (such as social media, review sites, blogs, interactive websites, photo and video sharing platforms) that facilitated interactions between users and between users and suppliers. This has been further augmented by the arrival of smartphones or Web 3.0. Also, new social media platforms (for instance Google+ and Instagram) and interactive websites (for instance, TripAdvisor and Yelp) now offer a userfriendly platform and eased/facilitated the sharing of experiences and different viewpoints (DiaAndreu 2017). Pre-pandemic trends have indicated that tourists are more tech. savvy and Internet offers them opportunities to expand their knowledge base and seek added value for their time and money. They have been time constrained with a desire to do a lot within a limited period of time. Furthermore, the shift to Web 3.0 has taken human-computer interactions to the next level and broadened the scope of marketing opportunities for the tourism industry in terms of experiential and intangible offerings by engaging customers with products and services in a variety of novel ways. This has enabled the creation of 3D (three dimensional) graphic and 
avatar-driven virtual worlds (Go \& Gretzel 2010) with the most prominent being Second Life. Relating the aforementioned advancements in technology and interactive digital platforms in the current lock-down environments, it cannot be denied that digitalization is playing a key role in shaping the views and responses of the public. It, in fact, has been and continues to be only link to the outside world and friends and relatives especially for quarantined people.

Clearly, information sharing, digital outreach and online marketing have become more crucial in today's era of social distancing. To keep, tourism live in the minds of targeted audience, tourism experiences need to be extensively synergized with artificial intelligence and virtual and augmented reality. Small micro enterprises (SMEs) should find creative ways to partner with virtual corporations and facilitate consumer attention and engagement. An important element of a transformational tourism system is dissemination of information and its accessibility. However, unlike most of the Western countries and advanced parts of the rest of the world, several places across the globe are still not tech savvy. Their level of interest and acceptance needs to determined and guided towards a progressive path. A technology acceptance model (TAM), pioneered by Davis (1989) is based on two factors that measure user acceptance of technology: perceived utility (user's views of superior performance because of technology) and perceived easiness of use (perceived level of difficulty a user is likely to face with the application) (Koufaris 2002). Developing countries and remote areas of the developed world, have been slow in embracing digitalization, partly because of lack of means and partly because of lack of training. The TAM model can prove to be useful in promoting and assessing the acceptance level of marginalized communities.

Perceived ease of use and usefulness of virtual applications are directly linked to flow experience (Liu et al. 2009; Lu, Zhou \& Wang 2009). Flow can be described "an optimal experience, the holistic sensation that people feel when they act with total involvement" (Csikszentmihalyi 1975, p. 36). Novak et al. (2000) report that flow has a positively effect on consumer behavior. Therefore, the preparedness for future travel calls for ongoing engagement, as people continue to be restricted prefer to remain (as parts of the world open to the first phase) within their local environments and home thresholds. To some extent, enjoyable wellness programs are being offered through digital platforms such as zoom (Inner Vision 2020). However, they are happening in an isolated manner. The destination marketing organizations have still to strategies 
partnership synergies with them to develop collaborative messages that support the broader society's wellbeing, promote at-home leisurely activities that relax body, mind and soul. These initiatives can augment preparedness for future travel. In this paper, the transformative potential of one therapeutic intervention catalyst (yoga) is discussed because of its restorative qualities and unprecedented popularity in the west.

\subsubsection{Yoga - new health norm}

Yoga emerged, in the pre-covid-19 era, as a popular form of wellness tourism. Wellness tourism can be broadly defined as "travel for the purpose of stimulating health and well-being through physical, psychological or spiritual undertakings" (Karn and Swain 2017, p. 2). It is motivated by pursuit of self wellbeing. Extant literature argues that yoga as a mental and physical pursuit unites body, mind and spirit and in doing so, generates a range of physiological and psychological benefits. Therapeutic benefits of this practice are recognized by many scholars. For instance, it helps to treat "lower back pain, rheumatoid arthritis, multiple sclerosis, cancer, diabetes, eating disorders, obesity, hypertension, symptoms of menopause, scoliosis, anxiety, depression, asthma, and the management of stress. Regular yoga practice has multiple benefits for people of all ages and "it is a personal and introspective activity" (Patterson, Getz \& Gubb 2016, 300, 301; Yoga Alliance 2016).

Yoga connotes intertwining of health, therapy, spirituality and healing (Oznalbant and Alvarez 2019; Patterson, Getz \& Gubb 2016). Number of yoga practitioners, across the globe, continue in the upward trajectory (Maddox 2015; Sharma \& Nayak 2019). A nationwide study, Yoga in America, was conducted by Yoga Journal (the California Yoga Teachers Association founded the Yoga Journal in 1975) and Yoga Alliance (an international nonprofit association, established almost two decades ago). The purpose was to broaden the understanding of the yoga practice in America and to gather insights on Americans perceptions of yoga. The study population was yoga practitioners, teachers, and yoga studio owners. Also, views of the non-patronizing section of the US public were ascertained. It was found that approximately $\$ 36.7$ million Americans pursued yoga in 2016. Key highlights from the study are presented below: 
- 34 percent of Americans say they are somewhat or very likely to practice yoga in the next 12 months - equal to more than 80 million Americans

- 37 percent of practitioners have children under the age of 18 who also practice yoga

- Students spend \$16B/year on classes, gear, and equipment, up from \$10B in 2012

- Women represent 72 percent of practitioners; men, 28 percent

- Practitioners are significantly more involved in many other forms of exercise, such as running, cycling and weightlifting, than non-practitioners

- 30-49 years old patrons make up 43 percent of the practicing public, followed by those ages $50+(38$ percent) and 18-29 (19 percent)

- 74 percent of American practitioners have been doing yoga for five or fewer years

- The top five reasons for starting yoga are: flexibility (61 percent), stress relief (56 percent), general fitness (49 percent), improve overall health (49 percent), and physical fitness (44 percent)

- 86 percent of the practitioners self-report having a strong sense of mental clarity, 73 percent report being physically strong, and 79 percent give back to their communities all significantly higher rates than among non-practitioners (Yoga Alliance 2016).

Clearly, Americans acknowledge the therapeutic benefits of yoga. The growing demand for yoga had resulted in a vast array of holiday/retreat options, seminars and festivals across the United States. It has been recognized as a serious leisure activity and as a positive psychology tool in the US since 1960s. It offers a unique view of opening a personal space for rejuvenating emotional, physiological and social aspects of life by integrating pranayama, asana, and meditation (Dillette, Douglas \& Andrzejewski 2019). Positive psychology looks at happiness. It offers scientific basis of good things in life and prosperity in the middle of adversity (Seligman and Csikszentmihalyi 2000). Seligman (2018) developed the PERMA model of wellbeing which embraces both hedonic and eudemonic dimensions. The hedonic view refers to the goal of seeking maximum pleasure and enjoyment. The eudaimonic view refers to a happy, self-fulfilling and the concept 
of leading a good life approach that holds potential to optimize meaningful behavior (Smith \& Diekmann 2017).

The PERMA model postulates that important factors promote the overall wellbeing, satisfaction toward life and happiness are: positive emotion (hedonistic aspects), engagement (psychologically connected to various aspects of life (such as work, institutions and actions/events), relationships (acclimatization with one's social environment and community), meaning (value for life and connection with the bigger universe- cosmos) and accomplishment (feeling of achievement based on progress towards set goals (Dillette et al. 2019; Seligman 2011). Dillette et al. (2019) report robustness of PERMA in steering towards higher levels of well-rounded/complete wellbeing and contend that yoga tourism leads to longer-term changes that contribute to overall well-being. More specifically, the authors identified transformational alterations within specific activities and catalysts. Yoga settings have offered an optimal environment to experience nature, time alone, meditation and yoga classes. Figure 1 presents a transformational catalyst paradigm, underpinned on the PERMA dimensions, to promote resilience and wellbeing of the visited/visiting communities. Ethical/equitable and preventive/ restorative production mechanisms are crucial.

Figure 1: Transformational Catalysts

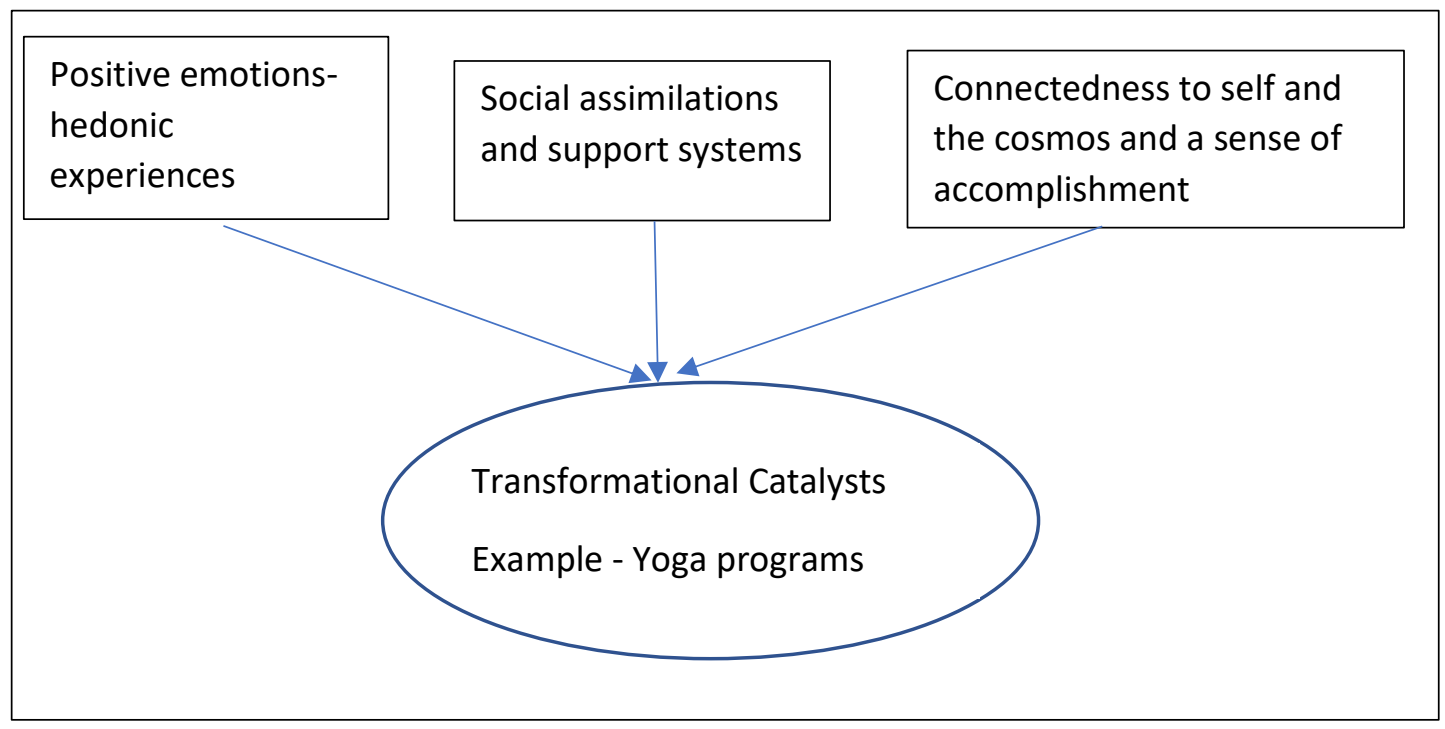

Source: After Dillette et al. 2019 
In relevance to their usefulness in the pandemic time, yoga retreat programs hold tremendous restorative and therapeutic potential to heal, build immunity, and offer relief from mental and physical fatigue (Patwardhan 2017). Their innovative initiatives carry double benefits. By being adaptive, they can survive the pandemic financially while at the same time, they can contribute to public health and wellbeing by engaging patrons at home through wellness programs and messages. From a tourism perspective, they can assist with preparedness for travel tomorrow. From a public health perspective, alternate healing and therapeutic mechanisms can contribute tremendously to the mental and physiological wellbeing of people, especially in times of crisis. However, adequate support is required as explained by Patwardhan:

Yoga can help, but before it can help, it needs help itself. The various stakeholders need to reflect and see the big picture so that they can collaborate.

In former times, coal miners carried a caged canary with them to the underground mines. Being highly sensitive to the poisonous gases in the mines, a canary's survival meant survival for the miners and prosperity for everyone above the ground. On the other hand, its distress or death was a harbinger of trouble for everyone. If our current socialpolitical-economic milieu can be seen as the metaphorical coal mine, then perhaps yoga is one of the canaries (2017, p. 178).

\section{Discussion}

Many people have traveled in search of self and anonymity, to lose themselves first and then to find themselves again (Smith \& Diekmann 2017, p. 6). Therapeutic landscapes have been often sought where the natural and built environment, social conditions and human interactions produce an atmosphere favorable to mental cleansing and physiological healing. The Campbell's (1985) mythical quest for the self involves three essential elements: reasons for departure, the initiation or the experience of transcendence and connectivity, and the return or the presentation of the transformed self back to society. The ripple effects of journeys of pre-pandemic yoga tourists upon return home and during pandemic times, are likely to influence/shape the life style and health habits of yoga tourists. Several scholars have noted that yoga practices transfer into their home life and many of them patronize local yoga centers while at the same time, practice 
yoga at home (Ali-Knight and Ensor 2017). For most of American yoga tourists, yoga has become a serious leisure pursuit (Yoga Alliance 2016) which they continue to pursue at home. It is increasingly considered to be a "body-self transforming practice" (Brown \& Leledaki 2010, p. 125). Therefore, alternate prevention/healing techniques, which can be referred as nonpharmaceutical interventions, require long-term investment and government support to optimize their contribution to public health. They can serve as transformational catalysts and diminish the devastating impact of COVD-19.

The future of transformational sustainable tourism in the post-crisis era is underpinned on the industry' ability and capability to bounce back with overarching focus on long-term health agenda for the tourism stakeholders and the broader society. According to the WHO, 'health is a state of complete physical, mental and social well-being and not merely the absence of disease or infirmity' (WHO 1948, no. 2, p. 100). Its 'Stay Home Today and Travel Tomorrow' campaign is a global outreach dialogue calling for the cooperation and ideas from entrepreneurs and innovators to mitigate Covid-19 shocks on tourism by planning and putting into action health, economic and destination revival solutions. According to the UNWTO Secretary General, "historically, tourism has proven itself as a key driver of international recovery, and as early as now, we must begin to prepare in order to build the foundations of the future resilience of tourism" (UN-WTO 2020).

In such times of a global crisis, strategies and paradigms investigating options for the enhancement of public health and wellbeing offer a crucial healing window that can focus on happiness, stress alleviation and future prosperity. All these outcomes are key to economic revival and growth. As the pandemic has shown, economic prosperity cannot be sustained if public health measures are weak; both are interdependent on each other. There is a need to provide value-added solutions to facilitate healing for good health, prosperity and happiness which are all important for healthy immune systems to enable sustainable travel tomorrow. Preparing for 'Tomorrow's Travel' calls for the tourism industry to build transformational resilient health systems that assist in countering the destructive elements of the current crisis (Ranasinghe et al. 2020).

The post-pandemic tourism will require stretching conventional parameters and developing transformational paradigms that highlight extended responsibility beyond the tourism 
environments and support optimal restoration and promotion of the health of the society at large, both in visited and visiting communities. The wellness tourism industry can also make an important contribution in times of crisis by developing, promoting and disseminating restorative programs to extended communities. The need is to become an important player in the extended social and public recovery programs. Therapeutic potential of restorative activities can be promoted and offered at home, on a broad scale, during the pandemic as it is expected to generate more waves of virus infections for a couple of years. Yoga is, for instance, undoubtedly a universal phenomenon and holds tremendous potential to build/guard mental and physical immunity from a healthy sustainable tourism perspective (Patterson, Getz \& Gubb 2016). However, many yoga programs are offered as an element of a broader wellness program (such as in gyms). Also, they are offered by small micro enterprises. The later will especially need public sector support to offer a variety of therapeutic programs on innovative digital platforms. The local government should lend credence and fund such programs.

Emerging scholarship on COVID-19 has offered several perspectives on a post-pandemic tourism system. However, no recent study has a offered a realistic systems approach that relates to the current lock-down and stay-at-home environments or places that are opening cautiously in the midst of warnings from public health experts. The core question that needs to be addressed is: what type of synergies can prevail right now to keep communities grounded, healthy, and reduces their stress levels. It is critical to advocate, on a large scale, 'stay-at-home' restorative mechanisms (including livestreaming outreach by different stakeholders of the travel and tourism industry) to successfully launch 'tomorrow's travel.'

Health is a personal obligation and is shaped by a person's outlook, perceptions and behavior. Aligned with this idea, it is argued that the subjective wellbeing of a person is related to harmony between the inner self and the physical body and the extended natural and cultural environments (Bushell and Sheldon 2009). According to Dutta-Bergman, health conscious persons are more inclined to pursue preventive and health-maintaining dispositions and stay committed to their wellbeing for their entire lifetime. Health consciousness can be described as a psychographic state of mind that is conscious of one's own health (Gould 1998) and refers to the extent to which "health concerns are integrated into a person's daily activities" (Jayanti and Burn 1998, p. 9). Health conscious people are frequent patrons of restorative and therapeutic programs and visit 
destinations that offer preventive and alternative healing opportunities. While travel today is on the halt, pursuing wellness activities and indulging in healthy leisure time can offer many benefits such as mental and physical wellbeing and demand for digital restorative programs/sessions based on yoga and meditation. Travel tomorrow can happen only if communities today are healthy. This study suggests a transformational wellness tourism system model (Figure 2).

Figure 2: A Transformational Wellness Tourism System

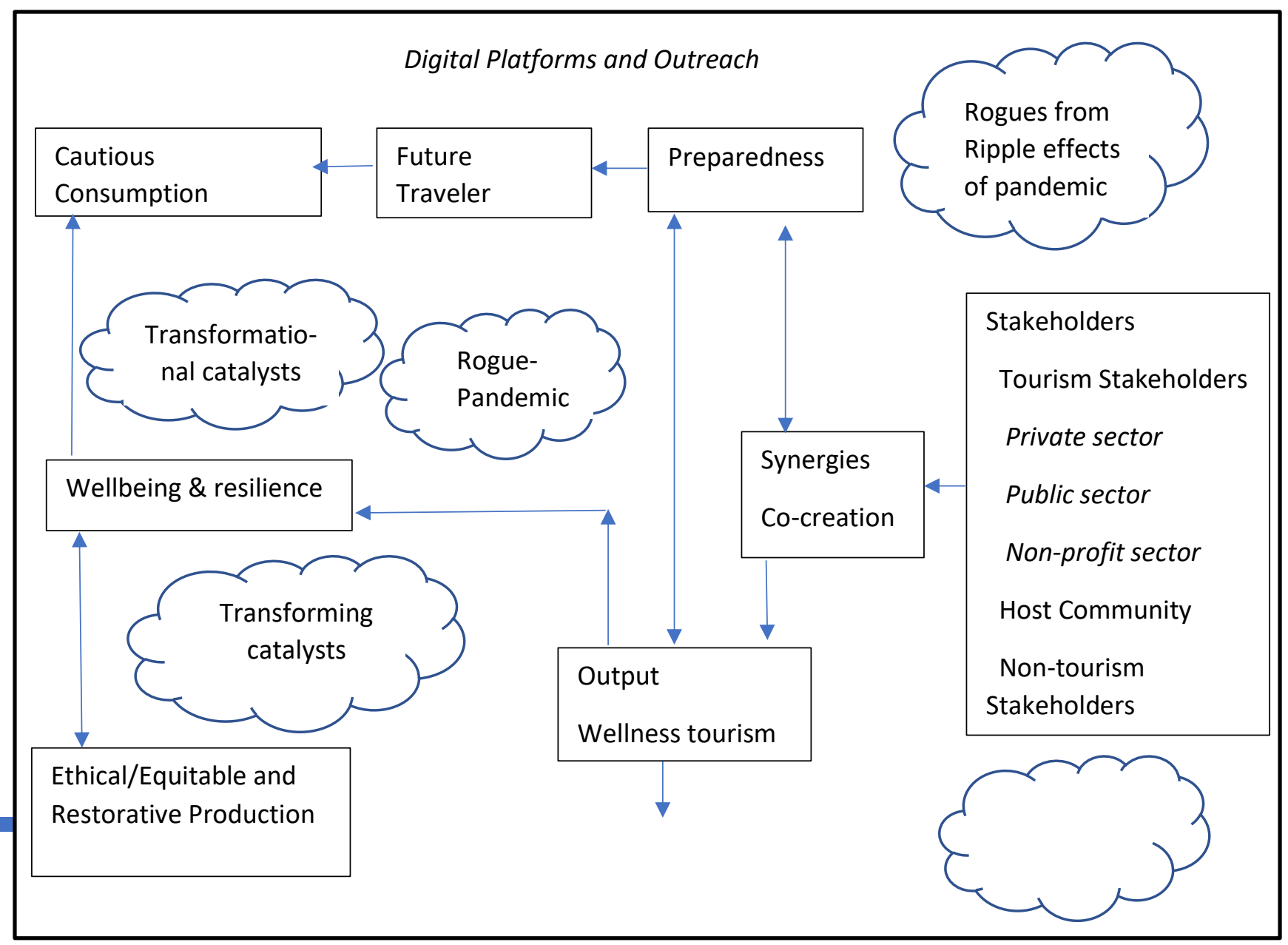


According to Brooker and Jopee (2014), health is a personal obligation and is shaped by a person's outlook, perceptions and behavior. Aligned with this idea, it is argued that the subjective wellbeing of a person is related to harmony between the inner self and the physical body and the extended natural and cultural environments (Bushell and Sheldon 2009).

Source: After McKercher (1999) and Chhabra (2015)

The Proposed system has six core components which are all, currently reliant on digital outreach mechanisms: stakeholders, synergies and co-creation strategies between them, wellness outputs (tourism attractions and experiences revolving around wellness), preparedness for future travel, the future traveler and wellbeing/resilience mechanisms developed by the suppliers. These components will continue to be impacted and shaped by rogues (chaotic interventions), the main one being the pandemic; other rogues are generated because of the ripple effects of the pandemic. The interventions and catalysts in the system are indicated by clouds. The digital platforms and digital outreach remain in the backdrop, offering crucial tools to facilitate interconnections and interactivity between the local, national and global communities. This transformative tourism system is an open system and is reliant on ethical/equitable and preventive/healing mechanisms to boost wellbeing and resilience of production and consumption patterns of tourism. For the resilience and wellbeing of tourism, tourism communities and the broader societies, social distancing and preventive/restorative mechanisms (such as yoga programs) are crucial. The key aim of the co-creation strategies between different stakeholders should be to support these mechanisms to prepare the future traveler.

Synergies between the tourism and non-tourism stakeholders will evolve as the system absorbs shocks and continues to be defensive and re-organizes itself because of the rogues. Three types of rogues are presented and the most powerful rogue is undeniably the pandemic which has generated a chain (ripple) effect by obstructing the local and global economies. Transforming catalysts can play the role of a band aid and various digital pillars (such as search engines, social media, websites, zoom etc.) offer the most secure option for authentic communication, connectivity and interactions. With regard to the life cycle curve, it can be argued that tourism has plunged because the entire system has been dislodged from a steady state after being hit by the pandemic. Several features of chaotic states can be applied to the current situation: the edge of the chaos phenomenon, the lock in state, and the self-organizing state. Tourism has reached a critical juncture of disequilibrium, and might remain in a lock-in and edge of chaos state for an 
extended period of time even after the pandemic subsides. It will take time to build consumer confidence (for instance, although many states in the United States are lifting the 'stay at home' order, the consumers are still reluctant to dine at the restaurants and/or patronize retail stores). Furthermore, as the new normal is embraced, niche forms of tourism are more likely to emerge. As an example, wellness tourism holds potential. But it will be shaped by the receptiveness of host communities as or when they plan to receive tourists and transition to the development stage of the TLC. Social exchange theory, social disruption theory and/or the social representations theory offer windows to meaningfully contextualize their response and support for niche tourism.

In the context of the Lamarckian model which postulates that all changes are heritable and living beings who best manage to adapt, are able to survive. However, this model will be tested once an effective vaccine is developed against COVID-19. The system will require the multiple pillars of digital support in the initialization and other preceding phases. In summary, the future of transformational sustainable tourism in the post-crisis era is underpinned on the industry' ability and capability to bounce back with overarching focus on long-term health agenda. According to Ateljevic (2020), new worlds are emerging at the threshold of current crisis advocating change and transformation, more specifically inner transformation which will give birth to novel ways of being, knowing and acting on this earth. While time for actual travel might be not be there, consumer interest can be digitally ignited through innovative marketing messages and online interactions. As an example, a marketing campaign in Alaska says: 'Alaska will be here when it is time to travel again. For today you will have to dream of the wide open-beauty Alaska provides.'

\section{References}

Ali-Knight, J. and Ensor, J. (2017). Salute to the sun: an exploration of UK Yoga tourist profiles. Tourism Recreation Research, 42:484-497.

Ateljevic, I. (2020) Transforming the (tourism) world for good and (re)generating the potential 'new normal.' Tourism Geographies, DOI: 10.1080/14616688.2020.1759134

Bai, Y., Yao, L., Wei, T., Tian, F., Jin, D.-Y., Chen, L., \& Wang, M. (2020). Presumed asymptomatic carrier transmission of COVID-19. JAMA, 323(14), 1406. https://doi.org/10.1001/jama.2020.2565

Baggio, R. (2008). Symptoms of Complexity in a tourism system. Tourism Analysis, 13(1), 1-20.

Berry, B., Gamieldien, J., \& Fielding, B. C. (2015). Identification of new respiratory viruses in the new millennium. Viruses, 7(3), 996-1019. https://doi.org/10.3390/v7030996 
Bloom, D. \& Cadarette, D. (2019). Infectious Disease Threats in the 21st Century: Strengthening the Global Response. Frontiers in immunology, 10, 549. doi:10.3389/fimmu. 2019.00549.

Brown, D. \& Leledaki, A. (2010). Eastern movement forms as body-self transforming cultural practices in the West: Towards a sociological perspective. Cultural Sociology, 4(1), 123-154.

Burkle, F. (2006). Globalization and disasters: Issues of public health, state capacity and political action. Journal of International Affairs, 59(2), 231-265.

Bushell, R. \& Sheldon, P. (Eds.). (2009). Wellness and tourism: Mind, body, spirit, place. Cognizant Communication.

Campbell, J. (1985). To sing the song, to tell the tale: A study of Toni Morrison and Simone Schwarz-Bart. Comparative Literature Studies, 22(3), 394-412.

Childers, T., Carr, C., Peck, J., \& Carson, S. (2002). Hedonic and utilitarian motivations for online retail shopping behavior. Journal of Retailing, 77(2001), 511-535. Retrieved from http://www.sciencedirect.com/science/article/pii/S0022435901000562

Chhabra, D. (2010). Sustainable Marketing of Cultural and Heritage Tourism. London: Routledge.

Chhabra, D. (2015). Strategic marketing in hospitality and tourism: Building a'SMART'online agenda. Nova Science Publishers, Inc.

Davis, F. (1989). Perceived usefulness, perceived ease of use, and user acceptance of information technology. MIS Quarterly, 13(3), 319-340

Dillette, A., Douglas, A. \& Andrzejewski, C. (2019) Yoga tourism - a catalyst for transformation? Annals of Leisure Research, 22:1, 22- 1, DOI: 10.1080/11745398.2018.1459195

Dutta-Bergman, M. J. (2004). Primary sources of health information: Comparisons in the domain of health attitudes, health cognitions, and health behaviors. Health communication, 16(3), 273288.

Go, H. \& Gretzel, U. (2010). Tourism Marketing Opportunities in Virtual Worlds: The Case of Second Life. Retrieved March 2013 from: http://sites.Google.com

G€ossling, S., Scott, D., \& Hall, C. (2020). Pandemics, tourism and global change: A rapid assessment of COVID-19. Journal of Sustainable Tourism. 10.1080/09669582.2020.1758708

Gould, W. (1998). African mortality and the newurban penalty'. Health \& place, 4(2), 171-181.

Gretzel, U. (2011). Intelligent Systems. Annals of Tourism Research, 38(3), 757-779.

Gunn, C. (1979). Tourism Planning. New York: Crane Russack.

Hall, C. (2006). Tourism, biodiversity and global environmental change. In S. G€ossling \& C. M. Hall (Eds.), Tourism and global environmental change: Ecological, economic, social and political interrelationships (pp. 142-156). Routledge.

Hall, M., Scott, D. \& Gössling, S. (2020): Pandemics, transformations and tourism: be careful what you wish for. Tourism Geographies, DOI: 10.1080/14616688.2020.1759131

Higgins-Desbiolles, F. (2020): Socialising tourism for social and ecological justice after COVID19. Tourism Geographies, DOI: 10.1080/14616688.2020.1757748 
Jayanti, R. \& Burns, A. (1998). The antecedents of preventive health care behavior: An empirical study. Journal of the academy of marketing science, 26(1), 6-15.

Jonas, O. (2014). Pandemic risk. World Bank.

Keogh-Brown, M., Smith, R., Edmunds, J., \& Beutels, P. (2010a). The macroeconomic impact of pandemic influenza: Estimates from models of the United Kingdom, France, Belgium and The Netherlands. The European Journal of Health Economics, 11(6), 543-554. https://doi.org/10.1007/s10198-009-0210-1

Kim, D., Park, J. \& Morrison, A. (2008). A model of traveller acceptance of mobile technology. International Journal of Tourism Research, 10(5), 393-407

Koufaris, M. (2002). Applying the technology acceptance model and flow theory to online consumer behavior. Information Systems Research, 13(2), 205-223.

Labonte, R., Mohindra, K., \& Schrecker, T. (2011). The growing impact of globalization for health and public health practice. Annual Review of Public Health, 32(1), 263-283. https://doi.org/10.1146/annurev-publhealth-031210101225

Leiper, N. (1979). The framework of tourism: Towards a definition of tourism, tourist, and the tourist industry. Annals of tourism research, 6(4), 390-407.

Leiper, N. (1990). Tourism System: An Inter disciplinary Perspective Department of Management System business Studies Faculty.

Li, R., Pei, S., Chen, B., Song, Y., Zhang, T., Yang, W., \& Shaman, J. (2020). Substantial undocumented infection facilitates the rapid dissemination of novel coronavirus (SARS-CoV2). Science, doi: 10.1126/science.abb3221

Little, J. 2012. Transformational tourism, nature and wellbeing: New perspectives on fitness and the body. Sociologia Ruralis, 52:257-271.

Lu, Y., Zhou, T. \& Wang, B. (2009). Exploring Chinese users' acceptance of instant messaging using the theory of planned behavior, the technology acceptance model, and the flow theory. Computers in Human Behavior, 25(1), 29-39. http://dx.doi.org/ 10.1016/j.chb.2008.06.002

Maddox, C. (2015). Studying at the source: Ashtanga yoga tourism and the search for authenticity in Mysore, India. Journal of Tourism and Cultural Change, 13(4), 330-343.

McKercher, B. (1999). A Chaos Approach to Tourism. Tourism Management, 20, 425-434.

McKercher, B., \& Chon, K. (2004). The over-reaction to SARS and the collapse of Asian tourism. Annals of Tourism Research, 31(3), 716-719.

Mill \& Morrison (2006). The Tourism System. Sydney: Prentice-Hall International.

Nicolaides, C., Avraam, D., Cueto-Felgueroso, L., Gonzalez, M. C., \& Juanes, R. (2019). Handhygiene mitigation strategies against global disease spreading through the air transportation network. Risk Analysis, 40(4): 723-740. https://doi.org/10.1111/risa.13438

Novak, T., Hoffman, D. \& Yung, Y. (2000). Measuring the customer experience in online environments: a structural modeling approach. Marketing Science, 19(1), 22-42.

Öznalbant, E. \& Alvarez, M. (2019). A socio-cultural perspective on yoga tourism. Tourism 
Planning \& Development, 1-15.

Patterson, I., Getz, D. \& Gubb, K. (2016). The social world and event travel career of the serious yoga devotee. Leisure Studies, 35(3), 296-313.

Popescu, M., Nicolae, F. \& Pavel, M. (2015). Tourism and hospitality industry in digital era:

Prigogine, I. \& Stengers, I. (1985). Order Out of Chaos [preface]. London: Flamingo

Ranasinghe, R., Damunupola, A., Wijesundara, S., Karunarathna, C., Nawarathna, D., Gamage, S., ... \& Idroos, A. A. (2020). Tourism after Corona: Impacts of Covid 19 Pandemic and Way Forward for Tourism, Hotel and Mice Industry in Sri Lanka. Hotel and Mice Industry in Sri Lanka (April 22, 2020).

Ravenscroft, N., \& Hadjihambi, I. (2006). The implications of Lamarckian theory for the TALC model. In R. W. Butler (Ed.). The tourism area life cycle (Vol. 2, pp. 150-163). Bristol: Channel View Publications

Rothe, C., Schunk, M., Sothmann, P., Bretzel, G., Froeschl, G., et al. (2020). Transmission of 2019-nCoV Infection from an Asymptomatic Contact in Germany. New England Journal of Medicine, 382(10), 970-971. https://doi.org/10.1056/NEJMc2001468.

Rudas, I. \& Fodor, J. (2008). Intelligent Systems. International Journal of Computers, Communication \& Control, III (Suppl.). Proceedings of ICCC, 132-138.

Sharma, P., \& Nayak, J. K. (2019). Do tourists' emotional experiences influence images and intentions in yoga tourism?. Tourism Review.

Russsell, R. (2006). Chaos Theory and Managerial Approaches. In D. Buhalis \& C. Costa (Eds.), Tourism Dynamics, Challenges and Tools: Present and Future Issues (108-115). Oxford: Butterworth-Heinemann.

Russy, D. \& Smith, R. (2013) The economic impact of H1N1 on Mexico's tourist and pork sectors. Health Economics, 22(7), 824-834. doi: 10.1002/hec.2862

Siu, A., \& Wong, Y. R. (2004). Economic impact of SARS: The case of Hong Kong. Asian Economic Papers, 3(1), 62-83. https://doi.org/10.1162/1535351041747996

Seligman, M. (2018). PERMA and the building blocks of well-being. The Journal of Positive Psychology, 13(4), 333-335.

Stebbins, R. (2001). Serious Leisure. Society, 38, 53-57.

Strielkowski, Q. (2020). Recovery strategy for tourism industry. doi: 10.13140/RG.2.2.19039.82086

UNWTO. (2020). COVID-19: UNWTO calls on tourism to be part of recovery plans. https://www.unwto.org/news/ covid-19-unwto-calls-on-tourism-to-be-part-of-recovery-plans.

Viboud, C., \& Simonsen, L. (2012). Global mortality of 2009 pandemic influenza A H1N1. The Lancet Infectious Diseases, 12(9), 651-653. https://doi.org/10.1016/S1473-3099(12)70152-4

WHO. (2020). Coronavirus disease 2019 (COVID-19): Situation Report 46. Available at: https://www.who.int/docs/default-source/coronaviruse/situation-reports/20200306-sitrep46covid-19.pdf?sfvrsn=96b04adf_2 (accessed 25.04.2020) 
World Bank. (2012). People, pathogens and our planet: Volume 2 - the economics of One Health. World Bank.

Wilder-Smith, A. (2006). The severe acute respiratory syndrome: impact on travel and tourism. Travel Medicine and Infectious Disease, 4(2), 53-60. https://doi.org/10.1016/j.tmaid.2005.04.004

Wu, T., Perrings, C., Kinzig, A., Collins, J. P., Minteer, B. A., \& Daszak, P. (2017). Economic growth, urbanization, globalization, and the risks of emerging infectious diseases in China: A review. Ambio, 46(1), 18-29. https://doi.org/10.1007/s13280-016-0809-2. 